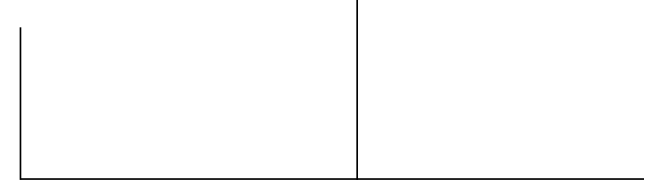

Rev. Latinoam. Psicop. Fund. III, 4, 156-164

\title{
Breves reflexões a respeito do sofrimento* \\ (aspecto pático da existência)
}

\author{
Eugène Minkowski
}

\begin{abstract}
O sofrimento é uma parte integrante da existência humana. Mais que uma parte, ele a marca, a posiciona. O sofrimento faz sofrer, e isso não é de forma alguma uma tautologia. Machuca, e como! Mas é uma dor que não saberíamos comparar a nenhuma outra. É do domínio do pathos humano e nele o homem reconhece seu aspecto humano.

Como toda dor, o sofrimento deveria ser evitado. Mas ele absolutamente não se submete a esses parâmetros. Ele está aí e nos faz sofrer. Como parte integrante da existência, poderia ele ser considerado uma necessidade? Também não coloca-se sob esse parâmetro. O que é necessário é determinado, como que imposto de fora. Não se escapa dele de forma alguma. É necessário percorrer esse caminho, quer se queira, ou não; devemos fazê-lo. Não devemos em absoluto sofrer. Sem dúvida, o sofrimento pode estar relacionado a um acontecimento exterior. Essa não é de forma alguma sua única origem. E o acontecimento exterior, pelo próprio fato de nos fazer sofrer, deixa de ser um simples acontecimento como os outros. Nós mesmos nos en-

* Tradução de Maria Vera Pompeo de Camargo Pacheco e revisão técnica do prof. dr. Mário Eduardo Costa Pereira (Laboratório de Psicopatologia Fundamental-Unicamp), de E. Minkowsli, "Brèves réflexions sur la souffrance”. In Traité de psychopathologie (Tratado de psicopatologia). Plessis-Robinson, Institut Synthélabo, 1999, p. 801-
\end{abstract} 813. 
contramos nele profundamente comprometidos. O sofrimento está em nós e nele tomamos contato com nós mesmos e com a existência. Não miséria humana, mas sofrimento humano. O homem que sofre não tem nada de mísero em si. Ele é o que é como ser humano, e o que não pode deixar de ser.

Não se trata em absoluto de aceitá-lo e ainda menos de buscá-lo ou mesmo de com ele comprazer-se. Todas essas condutas não estão de modo algum em sua escala. O sofrimento não é feito para isso. Ele está presente e nos revela o que é. O sofrimento pode determinar um estado depressivo, nos acabrunhar, provocar um sentimento de profundo desamparo. São reações pelas quais ele pode se traduzir, às quais ele pode dar lugar. Não é ainda, de maneira nenhuma, o próprio sofrimento.

Pode-se atravessar a vida sem jamais ter-se estado doente. Não se pode atravessá-la sem sofrer. Constatação empírica simplesmente? Se a vida fosse melhor organizada, o homem sofreria menos ou talvez mesmo não sofreria nem um pouco. No entanto, o homem por sua essência, irá sempre conhecer o sofrimento. Ele vem fundar sua existência. O homem pode ser poupado pelas doenças, extinguir-se um dia, como uma vela, de velhice. É raro, mas pode acontecer. Se, por acaso, chegássemos a pensar que um homem tenha sido poupado pelo sofrimento, no fundo seria dizer que ele não soube sofrer. E isso seria grave para ele.

Sob a pena de Balzac lemos o seguinte: "Aqueles que muito sofreram, viveram muito”. O sofrimento coloca-se, assim, em perspectiva sobre o vivido e isso não é dizer pouca coisa. Mas ele o faz tanto mais em relação ao autêntico e, nesse sentido, ao precioso na vida, ao sério e ao grave dessa vida. Teria ele, então, um valor positivo? Não se escapa da influência das justaposições racionais; elas, no entanto, não estão jamais à altura das correlações no plano do vivido.

O sofrimento não é certamente um bem, mas não é também um mal no sentido banal do termo. Não é nem um e nem outro, ou os dois de uma vez. Dói, e como!, mas a partir dele, o homem depara-se com problemas que sua existência coloca diante de si e o reconhece. Em si mesmo, o sofrimento não tem nenhum sentido - também, como teria ele um sentido? -, mas por meio dele coloca-se o problema do sentido da vida.

Assim, também, o sofrimento vem integrar-se ao dinamismo da vida, antes de mais nada em seu aspecto afirmativo. Nem ele e nem nada mais, de resto, poderia comprometer esse aspecto, uma vez que até mesmo nas vidas individuais nós teríamos de conhecer reações de abatimento e de desesperança. "O tempo cura os ferimentos.” Está ainda por ser comprovado. Em todo caso, isso não poderia ser nem esquecimento e nem simples retraimento: é muito mais a integração "natural” no mundo da vida, que encontra-se assim enfocada. E nós, com certeza acharíamos particularmente deslocado, e mesmo ridículo, se alguém tentasse determinar, no plano estatístico, quanto tempo em anos, semanas e horas, é preciso 
em média para "curar os ferimentos". É que o sofrimento, como todo fenômeno fundamental, destaca-se do que está em movimento e do que é vivo, sem que se possa traduzi-los em cifras e talvez nem mesmo em palavras.

Nós já falamos da rigidez, da imobilidade do sofrimento moral do melancólico. Nessa situação, o sofrimento nos choca e nos "prende", nós nos sentimos desorientados. Mas mesmo na vida comum podemos nos sentir "presos" de maneira semelhante na presença de uma reação aparentemente imobilizada, por mais atroz mesmo que seja a prova. Existem situações em que não resta nada para o ser humano, mas absolutamente nada de seus afetos; ele está "só". No entanto, ainda aí, se ele apenas permanecer mostrando sua face lacrimosa ao mundo ao seu redor - aliás, quem sabe se nós em seu lugar saberíamos fazer melhor, em todo caso nós não poderíamos julgá-lo por essa atitude -, a impressão de imobilidade poderá se destacar. A ressonância, o eco, em sua viva mobilidade, não conseguirão mais colocar-se inteiramente no diapasão dessa fixidez. Certamente, para tanto não renunciaremos nem à compaixão, nem à necessidade de socorrer. No "encontro" humano, uma espécie de brecha parece no entanto produzir-se. Isso não quer absolutamente dizer: "já é hora de você se consolar, de pensar em outra coisa”; um conselho dessa ordem soaria falso. Diríamos que, para o interessado, o debate deveria de preferência desenrolar-se interiormente, a sós consigo mesmo. E isso, novamente, não no sentido que gostaríamos, quase em nosso próprio interesse, ou até mesmo por outra coisa, mas porque a vida, em seu caráter afirmativo, parece querer pedir precisamente essa "outra coisa", ainda que seja apenas possível dar "conselhos" a esse respeito. Essa fixidez é, no entanto, uma ligeira falha. Efetivamente, constatamos às vezes que a dor profunda e o debate íntimo que ela produz vão pari passu com uma atitude bem diferente em relação ao mundo ambiente. Entre os dois estabelece-se uma espécie de discordância que não é um "no entanto", no sentido estrito do termo, já que as duas vertentes não entram em luta, absolutamente não se combatem, e nesse sentido, estão até mesmo de acordo. No entanto, a situação não será por isso menos dolorosa; nós a sentiremos profundamente, até mesmo ao ponto de ficarmos surpresos por esse acordo no desacordo. Desacordo nesse sentido em que a "face voltada em direção ao mundo ambiente" poderá ser positiva, produtiva, mesmo rica eventualmente e, no entanto, acordo porque esta face virá novamente como que a alimentar-se do padecimento que se continua a dolorosamente a carregar em si. Face "pessoal-social", como teríamos desejo de chamá-la, bem diferente que a da socialização, e mais particularmente da socialização de nossas consciências, teoricamente, aliás, poderíamos dizer a nós mesmos (Charles Blondel), diferente porque muito mais viva, feita ainda de qualidades, de fatores mais vibrantes, mais pessoais, mais criativos, do que são as relações sociais comuns. As coisas vão em muito maior profundidade. Elas são do domínio do existencial, do apelo que a “existência” nos lança. Às vezes, a esse respeito, 
será o caso de ter coragem. Esse termo, no entanto, não parece traduzir fielmente o real estado das coisas. Não é que se "suporte", que se faça oposição às vicissitudes inevitáveis da existência. Não há nem mesmo esforço propriamente dito, dir-se-ia que as coisas acontecem sozinhas, em função evidentemente daquilo de pessoal e de ativo que se carrega em si. É a vida, em seu dinamismo, que funda nossa existência e não o inverso. Reencontramos aí o que dizíamos da camada afetivo-social.

A dor física indica sempre um desequilíbrio, alguma coisa que não vai bem; é muito indicado tomar medidas para combatê-la, para eliminar sua causa. O sofrimento não é absolutamente sinal de desequilíbrio, não há nada de anormal nele. Ele faz "normalmente" parte de nossa existência.

O bom humor opõe-se ao mau humor, a sorte ao azar, a alegria à tristeza, a atividade à passividade, a afetividade vibrante e generosa à indiferença, a saúde à doença, o sofrimento não tem absolutamente antônimo. A felicidade?, estado de alma fugaz e passageiro, inatingível; é com dificuldade que ousamos escrever essa palavra, tamanha a fragilidade daquilo que esta visa. A felicidade apenas toma um pouco mais de consistência, no momento em que, para além dos fatos e dos fatores isolados, ela dirige-se a um conjunto, a uma síntese, situada fora das misérias da vida. Dias felizes, união feliz, união infeliz no outro extremo. Ao contrário da dor (dolorosa), o sofrimento* por razão evidente, de forma alguma cria adjetivo. Ele está presente, “à mão”, palpável, em sua alma, a atravessa de alto a baixo, parece às vezes dobrar-se sob seu fardo.

Nesse ponto a existência humana separa-se do devir biológico. O “mal” não tem mais absolutamente o mesmo sentido.

A partir do sofrimento humano, abre-se para nós o aspecto "pático" (e não patológico) da existência. Esse aspecto "pático” atravessa-a mesmo, de alto a baixo, marca-a, torna-a humana.

A "pena” e o verbo neutro "penar"1; penando nós avançamos na vida, nós somos feitos para isso, e isso dá a esse avanço seu verdadeiro sentido. De outra forma, tudo nos cairia como o maná celeste e provavelmente não teria mais, a nossos olhos, o mesmo valor. Com certeza, penar não é o que poderíamos chamar de um acontecimento divertido e agradável, mas não é tampouco um "mal-estar”. A possibilidade de avançar assim, a brecha que ele contém em direção ao futuro nunca se tem certeza de ser bem sucedido - revalorizam de fato esse "penar", apesar de seu caráter pático, e talvez até mesmo em razão dele, um fator constitutivo da existência.

* Souffrance, no original francês (N. da T.)

1. O verbo penar, Jornal de psiquiatria infantil, Bâle, XIV, 6, 1947. 


\section{Alguns fenômenos páticos}

\section{A nostalgia}

A nostalgia deve também encontrar seu lugar aqui. Nenhum manual de psicologia fala dela. É, no entanto, um dos fenômenos essenciais da existência. Refere-se à “perda”, à perda do que nos é caro e precioso, nostalgia-saudade de casa (nostalgie-mal du pays), e como ilustração em nossa área, as depressões reativas das “domésticas interioranas”, incapazes de se adaptarem à vida da capital. Já será diferente a nostalgia do exilado político: mais vibrante, mais rica e mais "extensa”. Mas aqui como lá, a nostalgia terá os "lugares” como suporte, evidentemente com tudo o que no plano afetivo, gravita ao redor deles. Ela conterá a possibilidade, o desejo de um retorno. A nostalgia pode, no entanto, ir muito mais longe, ter como tema uma perda irreparável, uma perda que nada mais poderia substituir. Sim, ela pode inclusive concernir bens que, em verdade, nunca se possuiu.

Em vista de um presente que nos oprime, do mal que os homens conseguem perpetrar com suas próprias mãos, até graus monstruosos, a nostalgia de tempos melhores surgirá desse melhor que nossas aspirações nos revelam e para as quais somos feitos. A nostalgia de bens perdidos contém, mesmo que seja apenas em forma de esboço, uma nostalgia de bens procurados e por essa via abre uma brecha, apenas uma pequena brecha, mas ainda assim uma brecha, em direção ao futuro.

A nostalgia é incontestavelmente um sentimento doloroso. O próprio nome o indica. Mas não é apenas isso. Da mesma forma que "penar", parece comportar uma "abertura" em direção ao futuro e aí manifestar seu alcance positivo, não no sentido estrito e "abstrato" do termo, pois esse aspecto positivo não lhe retira em absoluto seu caráter doloroso. As operações aritméticas ainda menos que as oposições lógicas, não são aceitas aqui. A nostalgia comporta um desejo, uma procura, mas não um desejo que desabrocha de si mesmo livremente, que se afirma assim, apenas com o risco de encontrar obstáculos em seu caminho; o desejo permanece nostálgico, nessa nostalgia ele começa a nascer, encontrando nela, em seu aspecto doloroso, como uma barreira até a impossibilidade material para esse livre desabrochar, do qual acaba de tornar-se questão.

Ele procura aí seu caminho, tanto mais que não vai efetivamente em direção a um objetivo preciso. O que não impede que, dessa maneira, ele oriente-se em direção ao futuro e venha integrar-se à caminhada da vida. Sem possibilidade de realizar-se lá, onde repousa sobre o irreparável, na vida comum parece que ele sabe ceder lugar a condutas reparadoras, condutas que mereceriam um estudo à parte que nós não podemos desenvolver aqui. 
Mas é sobretudo o fenômeno da angústia humana que nós teremos a examinar e a situar sob o ângulo desse aspecto pático da existência. Aliás é com ela que mais freqüentemente temos de tratar no domínio da psicopatologia.

“A ansiedade (ou se quisermos, a angústia), escreve Henri Ey, é esse estado afetivo que se encontra em todas as reviravoltas da existência e sob todas as formas da existência humana”. Esta frase indica bem o lugar que cabe à ansiedade na existência. Fenômeno incontestavelmente pático, no entanto ela não é absolutamente patológica em suas origens. Daí, também, a maneira pela qual devemos concebê-la no domínio do patológico. O termo "reviravolta” parece significativo. A rigor, se podemos dizer que a memória intervém a cada instante - com as reservas que formulamos anteriormente quanto à legitimidade de tal asserção -, não nos referiremos certamente a ela como reviravoltas da existência. Uma prova a mais de que todas as manifestações psicopatológicas não poderiam ser subordinadas ao termo genérico de "transtornos", como o faz habitualmente a patologia geral. Nós já dissemos a propósito da afetividade, dando preferência ao termo "alterações”, após tê-la confrontado com a memória. É que existem transtornos e transtornos, em função precisamente dos fenômenos vitais aos quais elas se referem. A angústia humana, tão pouco quanto a afetividade, não poderia ser colocada unicamente lado a lado com a memória ou o julgamento. Uma rápida olhada, ao menos nós o acreditamos, nas funções, fenômenos e correlações importantes para um balanço, é suficiente para convencer-nos.

Aí também a psicopatologia, na medida em que refere-se à psicologia do pathos humano, retoma seus direitos, afirma sua autonomia. Ela terá de estudar certas reações páticas que ainda não têm nada de patológico em si, no sentido médico do termo. Embora às vezes pequenas, podendo mesmo no momento parecer mesquinhas, elas não deixam de se referir à existência humana.

No esboço de Em direção a uma cosmologia, intitulada "Ao avançar, deixo atrás de mim marcas em meu caminho”, eu escrevia:

Para o homem, a vida é uma estrada a ser percorrida e essa estrada não tem em si nada de metafórico. No fundo é a única estrada que eu devo necessariamente percorrer na vida, traçando-a e construindo-a inteiramente com minhas mãos. Naturalmente falaremos agora de reviravoltas em nossa estrada, se bem que essa estrada estenda-se reta diante de nós, ou ainda, de seguir a estrada certa, se bem que a estrada, por ser estrada humana, não possa ser senão a estrada certa.

Nessas reviravoltas, a ansiedade, em sua dimensão existencial, virá situar-se. A ansiedade é uma reação humana. Sempre a mesma, manifestando-se no momento oportuno em diversas situações, ela não se reduz absolutamente ao conjunto dessas experiências isoladas e não é absolutamente sua resultante. 
Pungente, dolorosa crispação interior, ela estreita o campo da consciência e ao mesmo tempo o da existência. Ela paralisa o livre desabrochar, determina um "universo ansioso" que lhe é próprio. Viva pois pungente, "nos apanhando pela garganta”, ela questiona nossa existência e coloca um problema a respeito de si. A ansiedade mórbida toca de perto a "angústia humana", fonte de reflexões e de meditações de ordem metafísica. É também por essas reflexões que Henri Ey encerra seu capítulo sobre a ansiedade.

As palavras de Kierkgaard, tão freqüentemente citadas, voltam à lembrança: "Ser passível desse mal coloca-nos acima do animal, progresso que nos diferencia mais particularmente que a postura vertical de caminhada”.

Reação patológica ou reação normal? Quem saberia dizê-lo? No fundo, uma e outra ao mesmo tempo. A linha de demarcação entre o "patológico", e não mais o normal, mas o "humano", é difícil de ser traçada. Da mesma forma, nós não falamos de transtornos da ansiedade, mas apenas de ansiedade mórbida. Geralmente a ansiedade vem mais causar agitação, perturbar a existência, do que caracterizarse como transtorno no sentido médico do termo. Mesmo denotando um "mal-estar", ela não é em absoluto uma doença. Considerá-la como um transtorno da emotividade, mesmo sem querer negar as ligações que podem existir entre as duas, seria voltar a subordinar um fenômeno maior no plano existencial a um fenômeno menor.

Guiraud começa seu capítulo sobre a ansiedade pela descrição do angor, referindo-se aos doentes descritos por Souques e que, acometidos por ataques coronarianos, apresentavam angústia sem ansiedade*. Não se trata absolutamente de colocar em questão o interesse de casos dessa ordem. No fundo é o mesmo caminho que Head e depois dele Mourgue seguiram em seus estudos sobre as alucinações. Ela solicita as mesmas reservas. Não se poderia apoiar sobre ela as pesquisas que tivessem relação com o fenômeno do mesmo nome, tal como apresenta-se em psicopatologia. E se Guiraud exprime a esperança de que o leitor não esperará de sua parte uma oposição de duas categorias de ansiedade - a ansiedade dita orgânica, de um lado, e, de outro, uma ansiedade dita psíquica ou psicogênica - gostaríamos de dizer que, em absoluto, não é tanto de uma oposição dessa ordem que se trata, quanto do prolongamento que naturalmente o fenômeno da ansiedade encontra na existência sob seu aspecto humano.

$\mathrm{O}$ angor, apenas como sintoma de um ataque coronariano ou de uma perturbação neurovegetativa, e ansiedade, fenômeno essencial na vertente humana,

* Na tradição psicopatológica francesa é freqüente a distinção entre angoisse (angústia) e anxiété (ansiedade). O primeiro termo refere-se sobretudo às sensações físicas dos estados ansiosos e o segundo a seus componentes psíquicos. (N. da T.) 
comportam um distanciamento. Aliás, isso não exclui o fato de que nos ataques de ansiedade, a respeito dos quais terei ainda de falar, o sistema neurovegetativo pode encontrar-se engajado de uma maneira ou de outra, sem constituir-se por isso em sua causa e sobretudo sem poder esgotar sua significação. A ansiedade de forma alguma parte desse ponto, ela desenvolve-se relacionada a uma situação e só pode ser examinada em função dessa situação.

"A doença não cria absolutamente a ansiedade mas, sob forma de estruturas neuróticas ou psicóticas, nos entrega àquela que cochila no fundo de nosso ser” (Henri Ey). Se ela fizesse apenas cochilar!

Há aí uma distinção a fazer: mesmo no curso de uma neurose de angústia, seria qualquer angústia necessariamente mórbida e a ser computada em função da neurose, ou, ao contrário, ela poderia proceder diretamente da angústia humana? Nós reencontramos aí o que dizíamos do nervosismo moral. Trata-se, aliás, de uma questão de ordem geral. Assim, ao longo de uma esquizofrenia, teremos de nos perguntar igualmente se todas as manifestações que podem ainda à primeira vista parecer anormais originam-se da afecção, e isto não apenas sob o ângulo da análise fatorial. Sentimentos humanos virão aí se misturar, submetendo-se inteiramente à eventual repercussão das modificações que a esquizofrenia comporta em sua maneira de ser. É uma questão de intuição daquele que deverá intervir na vida do angustiado (ou do esquizofrênico), e é aí que as doutrinas poderão passar ao lado da verdade.

Agora é preciso perguntar-se igualmente se a ansiedade, lá onde nos encontramos em presença do patológico, não serve de "revestimento" a uma perturbação sediada além desse ponto. A teoria da psicastenia de Pierre Janet pode nos servir de indicação nesse ponto de vista. Em todo caso, as manifestações menores e mais ou menos comuns de ansiedade, freqüentemente exageradas, originárias das naturais fraquezas humanas e sujeitas assim à cautela, não nos colocam de forma alguma na perspectiva de um estado de equilíbrio perfeito, isento de qualquer reação ansiosa, mas na de um fenômeno essencial de caráter pático, constitutivo de nossa própria existência. Nossas atitudes deverão inspirar-se nisso; a "filiação" das diversas manifestações deverá igualmente levá-lo em conta.

Não nos retardaremos muito na questão de saber como a ansiedade se apresenta nas diversas síndromes clínicas. A distância em relação ao seu sentido primeiro pode ser tão grande que a "ansiedade" não conserve mais muita coisa desse sentido, de suas características essenciais. Sobre o fundo esquizofrênico, a "ansiedade” situa-se mais freqüentemente no plano da narração do que no do vivenciado e no do experimentado. O mesmo acontece com o resto dos fenômenos obsedantes de natureza esquizofrênica, em que a luta interior, com o sentimento de angústia que ela desencadeia, cede lugar a uma justificativa abstrata e "desreal” desses fenôme- 
nos. Nesse sentido nós falamos de "topografia da angústia", ${ }^{2}$ sendo que o termo topográfico visa à maneira pela qual o sintoma estudado se situa em relação à pessoa. O plano da narração implica uma "distância” em relação a essa pessoa e, em seu caráter neutro e objetivo, a priva de suas observações subjetivamente vivas. Com isso, nós acrescentamos esse fato de que o esquizofrênico freqüentemente fala de si mesmo como se estivesse agindo por intervenção de uma terceira pessoa. De resto, isso não exclui absolutamente que, sobretudo nas fases iniciais, a ansiedade possa manifestar-se sob seu verdadeiro aspecto.

A ansiedade, como fenômeno essencial, comporta como que um despedaçamento específico. É como se houvesse nela duas estradas que se separam com violência, num antagonismo à primeira vista irredutível, determinando essa crispação pungente que a caracteriza. Que nós designemos agora as duas estradas: morte e vida, constrangimento ou entrave e livre desenvolvimento, complexo e força repressora, o modelo permanece o mesmo. Talvez deva-se apenas observar que ao nos orientarmos por explicações puramente individuais, passamos ao lado daquilo que, situando-se de imediato no plano existencial, as ultrapassa. Aí o psicologismo excessivo assemelha-se às explicações neurobiológicas e tropeça com as mesmas dificuldades. Os fenômenos constitutivos da vida não podem ser reduzidos a fatores unicamente individuais, quer sejam de natureza orgânica ou psicológica.

Em resumo, chega-se à questão de saber se nossa vida humana não é mais feita de "pático", de "esquizopático", do que de "fisiológico". Não se trata de forma alguma de pessimismo. Longe disso. Não se trata absolutamente de estabelecer um balanço, de colocar de um lado as receitas e de outro as despesas; as operações aritméticas não têm nada a ver com isso. As fórmulas racionais, as visões “abstratas” também não. No cadinho do sofrimento forma-se a pessoa humana; por aí ela se afirma. Mais além ela olha, mais além ela vê. Não é mais uma simples constatação de fatos decomponíveis. Nem pessimismo em desacordo com o sentido da vida, nem otimismo beato - no fundo são posições bem pequenas que ainda não dizem grande coisa -, mas tendência natural à afirmação e à confiança. E é uma coisa completamente diferente.

Esse aspecto pático da existência - e nós já o fizemos pressentir - atravessa a vida humana e de sua parte, nesse sentido, a fundamenta. E se o sofrimento humano é o que nos revela o aspecto mais aparente, mais dramático e mais "vivo", ele encontra-se numa forma menos "honrosa", se é permitido assim exprimir-se, até nas manifestações de ansiedade, da mesma forma que nas pequenas reações fóbicas ou obsessivas que encontramos tão freqüentemente em nosso caminho; elas dizem respeito à nossa condição humana e pedem para ser apreciadas sob esse ângulo.

2. Ann. méd.-psych., 108, I, 1950. 